\title{
BMJ
}

\section{Risk of ovarian cancer in women with symptoms in primary care: population based case-control study}

\author{
William Hamilton, consultant senior lecturer, Tim J Peters, professor, Clare Bankhead, university research \\ lecturer, Deborah Sharp, professor
}

NIHR School for Primary Care Research, Department of

Community Based Medicine,

University of Bristol, Bristol

BS8 2AA

Correspondence to: W Hamilton

w.hamilton@bristol.ac.uk

Cite this as: BMJ 2009;339:b2998 doi:10.1136/bmj.b2998

\section{ABSTRACT}

Objective To identify and quantify symptoms of ovarian cancer in women in primary care.

Design Case-control study, with coding of participants' primary care records for one year before diagnosis.

Setting 39 general practices in Devon, England.

Participants 212 women aged over 40 with a diagnosis of primary ovarian cancer, 2000-7; 1060 controls matched by age and general practice.

Main outcome measures Odds ratios and positive predictive values for symptoms from conditional logistic regression analyses.

Results Seven symptoms were associated with ovarian cancer in multivariable analysis. The univariable positive predictive values and multivariable odds ratios (with 95\% confidence intervals) for these were $2.5 \%$ (1.2\% to $5.9 \%)$ and 240 (46 to 1200) for abdominal distension; $0.5 \%$ (0.2\% to $0.9 \%$ ) and 24 (9.3 to 64) for postmenopausal bleeding; $0.6 \%$ (0.3\% to $1.0 \%)$ and 17 (6.1 to 50$)$ for loss of appetite; $0.2 \%$ ( $0.1 \%$ to $0.3 \%)$ and 16 (5.6 to 48$)$ for increased urinary frequency; $0.3 \%(0.2 \%$ to $0.3 \%)$ and 12 (6.1 to 22$)$ for abdominal pain; $0.2 \%(0.1 \%$ to $0.4 \%)$ and 7.6 (2.5 to 23$)$ for rectal bleeding; and $0.3 \%(0.2 \%$ to $0.6 \%$ ) and 5.3 (1.8 to 16) for abdominal bloating. In 181 (85\%) cases and 164 (15\%) controls at least one of these seven symptoms was reported to primary care before diagnosis. After exclusion of symptoms reported in the 180 days before diagnosis, abdominal distension, urinary frequency, and abdominal pain remained independently associated with a diagnosis of ovarian cancer.

Conclusions Women with ovarian cancer usually have symptoms and report them to primary care, sometimes months before diagnosis. This study provides an evidence base for selection of patients for investigation, both for clinicians and for developers of guidelines.

\section{INTRODUCTION}

Ovarian cancer accounts for $4 \%$ of all cancers in women, with over 200000 new diagnoses each year worldwide. ${ }^{1}$ It has the worst prognosis of all gynaecological cancers, with an overall five year survival of about $35 \% .^{2}$ In early cancers (FIGO (International Federation of Gynaecology and Obstetrics) stage I or II) survival is $80-90 \%$ compared with $25 \%$ in late cancers (FIGO III and IV). ${ }^{3}$ Currently only $30 \%$ of patients are diagnosed in these early stages. ${ }^{1}$ No effective screening test exists, ${ }^{4}$ so the main prospect for earlier diagnosis is improved identification of symptomatic cancer. ${ }^{5}$ The presentation of such symptoms is usually to primary care. ${ }^{6}$

Until recently, ovarian cancer was considered to have few symptoms, earning it the soubriquet of the "silent killer." Current referral guidance in the United Kingdom recommends urgent investigation only for abnormal vaginal bleeding and palpable masses, though these recommendations are not mandatory. ${ }^{7}$ Several recent studies have shown that symptoms are common, though they often go unrecognised by women and doctors. ${ }^{58}$ Abdominal pain, abdominal distension, pelvic pain, increased urinary frequency, constipation or diarrhoea, abnormal vaginal bleeding, weight loss, abdominal bloating, and fatigue have all been reported. ${ }^{49}$ Although few studies have defined the difference between abdominal distension and bloating, the generally accepted interpretation is that distension is a progressive increase in size, whereas bloating describes alternating increases and decreases in abdominal girth. Almost all studies of symptomatic ovarian cancer, however, have used interviews with patients after diagnosis, a method that often leads to recall or selection bias. ${ }^{6}$ Furthermore, the symptoms that have been identified are also common in non-malignant conditions, inasmuch as $95 \%$ of women attending primary care have a symptom potentially representing ovarian cancer. ${ }^{6}$

Only three studies have been based in primary care, each using medical records in the United States to identify symptoms. ${ }^{10-12}$ One positive predictive value, $0.3 \%$ for abdominal pain, was estimated. ${ }^{10}$ Positive predictive values are the chance that a woman with a symptom actually has ovarian cancer and are useful for clinicians when deciding whether to investigate. We designed this case-control study to be large enough for us to calculate positive predictive values for ovarian cancer for all important symptoms in primary care, both individually and in combination.

\section{METHODS}

\section{Participants}

We included women aged $\geq 40$ with primary ovarian cancer diagnosed in 2000-7 in England. All 50 general 
Table 1|Characteristics of women with ovarian cancer in primary care (cases) and matched controls. Figures are number (percentage) of women unless stated otherwise

\begin{tabular}{lcc}
$\begin{array}{l}\text { Characteristic } \\
\text { Age (years): }\end{array}$ & Cases $(\mathbf{n = 2 1 2 )}$ & Controls $(\mathrm{n}=\mathbf{1 0 6 0})$ \\
\hline $40-49$ & $19(9)$ & $98(9)$ \\
\hline $50-59$ & $46(22)$ & $224(21)$ \\
\hline $60-69$ & $61(29)$ & $308(29)$ \\
\hline $70-79$ & $50(24)$ & $250(24)$ \\
\hline$\geq 80$ & $36(17)$ & $180(17)$ \\
\hline Median (IQR) No of consultations/patient & \\
\hline Total & $10(6-14.75) *$ & $1(0-3)$ \\
\hline Days before diagnosis: & & $1(0-3)$ \\
\hline $1-90$ & $4(2-6)$ & $1(0-3)$ \\
\hline $91-180$ & $2(1-4)$ & $1(0-3)$ \\
\hline $181-270$ & $1(0-3)$ & \\
\hline $271-365$ & $2(1-3)$ & \\
\hline IQR=interquartile range. & & \\
$* P<0.001$, rank sum test. & & \\
\hline
\end{tabular}

practices in Exeter, mid-Devon, or east Devon, were invited to participate. The 39 that accepted had about 66500 female patients aged 40-69 and 31000 aged $\geq 70$, totalling 97500 . We identified cases by searching through practice computer systems. We identified histology records and accepted women without positive results on histology only if the records contained a specialist diagnosis based on strong clinical evidence. The date of diagnosis was taken as the date of positive histology results or as given by the specialist in those without histological confirmation.

Five controls for each case were matched by age (to one year) and practice with computerised random numbers. Controls were eligible if they were alive at the time of diagnosis of their matched case. Case and controls were excluded if the medical record was unobtainable, there was no entry in the records in the year before diagnosis, the woman had a previous ovarian cancer or bilateral oophorectomy, or they lived outside the study area at the time of diagnosis. Ineligible controls were replaced by reserve controls.

\section{Collection and coding of medical data}

For each woman with cancer we made anonymised photocopies of their full medical records for one year before diagnosis; the same was done for the matched controls. Three researchers, blinded to the status of each woman, coded all symptoms (whether or not they had previously been reported as associated with ovarian cancer), using the international classification of primary care- 2 , augmented by new codes for symptoms such as bloating. ${ }^{13}$ This classification system is the most symptom based of the primary care coding systems and has 17 chapters relating to different body systems, each with up to 30 relevant symptoms. The same researcher coded both cases and controls within each practice, to minimise the effect of any variation in coding style between observers. Variation was examined by all coders recoding 246 randomly selected symptom codes. The reliability coefficient was 0.79 (95\% confidence interval 0.75 to 0.83$).{ }^{14}$

\section{Analysis}

We studied only symptoms occurring in at least $5 \%$ of either cases or controls. Univariable conditional logistic regressions, with a $\mathrm{P}$ value $<0.1$, identified symptoms for multivariable analyses. As 99 of these were identified, we used a $\mathrm{P}$ value of $<0.01$ as the significance level for the multivariable analyses. At this stage, the symptoms were placed in eight clinical groups with a common theme, such as urinary symptoms. Each group was analysed by multivariable conditional logistic regression. Symptoms remaining

Table 2 |Frequency of selected clinical features* in women with ovarian cancer in primary care (cases) and controls. Figures are number (percentage) of women

\begin{tabular}{|c|c|c|c|c|c|}
\hline \multirow[b]{2}{*}{ Characteristic } & \multicolumn{3}{|c|}{ Cases } & \multirow[b]{2}{*}{$\begin{array}{l}\text { Controls } \\
(n=1060)\end{array}$} & \multirow[b]{2}{*}{ Likelihood ratio $(95 \% \mathrm{Cl})$} \\
\hline & All $(n=212)$ & $\begin{array}{l}\text { Stage I or II } \\
\quad(n=53)\end{array}$ & $\begin{array}{c}\text { Stage III or IV } \\
\quad(n=111)\end{array}$ & & \\
\hline \multicolumn{6}{|l|}{ Symptoms: } \\
\hline Abdominal pain & $112(53)$ & $29(55)$ & 66 (59) & $92(8.7)$ & 6.2 (4.9 to 7.8$)$ \\
\hline Abdominal distension & $77(36)$ & $18(34)$ & $39(35)$ & $6(0.6)$ & 65 (29 to 150$)$ \\
\hline Diarrhoea & $57(27)$ & $11(21)$ & $33(30)$ & $72(6.8)$ & $4.0(2.9$ to 5.5$)$ \\
\hline Loss of appetite & $44(21)$ & $3(6)$ & $28(25)$ & $16(1.5)$ & $14(8.0$ to 24$)$ \\
\hline Constipation & $42(20)$ & $6(11)$ & $27(24)$ & $40(3.8)$ & 5.3 (3.5 to 8.0$)$ \\
\hline Abdominal bloating & $35(17)$ & $3(6)$ & $25(23)$ & $21(2.0)$ & $8.4(5.0$ to 14$)$ \\
\hline Urinary frequency & $29(14)$ & $6(11)$ & $14(13)$ & $31(2.9)$ & $4.8(2.9$ to 7.7$)$ \\
\hline Postmenopausal bleeding & $28(13)$ & $11(21)$ & $11(10)$ & $12(1)$ & $12(6.1$ to 23$)$ \\
\hline Rectal bleeding & $18(8.5)$ & $5(9)$ & $8(7)$ & $16(1.5)$ & 5.7 (3.0 to 11$)$ \\
\hline \multicolumn{6}{|l|}{ Physical signs on examination: } \\
\hline Abdominal mass & $71(33)$ & $15(28)$ & $42(38)$ & $1(0.1)$ & 360 (50 to 2600$)$ \\
\hline Mass palpable vaginally & $18(8.5)$ & $2(4)$ & $12(11)$ & $2(0.2)$ & $46(11$ to 190$)$ \\
\hline Mass palpable rectally & $11(5.2)$ & $1(2)$ & $5(5)$ & $1(0.1)$ & $56(7.2$ to 430$)$ \\
\hline Abdominal tenderness & $51(24)$ & 10 (19) & $32(29)$ & $19(1.8)$ & 14 (8.2 to 23$)$ \\
\hline
\end{tabular}

*All features were more common in cases, P<0.001. 
associated with cancer after this first stage of analysis were rearranged into two larger groups (abdominal symptoms and other symptoms), and further modelling performed. All discarded symptoms were then checked against the final model by adding them individually to confirm that they did not add substantially to it with the likelihood ratio test. ${ }^{15}$ Finally, five clinically plausible interactions were tested in the final model.

We calculated positive predictive values for individual symptoms and for pairs of symptoms from the likelihood ratio and the national incidence of cancer in 2005. ${ }^{16}$ This incidence was 35.7/100 000 for women aged over 40, 29.6/100 000 for those aged 40-69, and $68.6 / 100000$ for those aged $\geq 70$. As all women in cases had consulted in primary care but $10.8 \%$ of eligible controls had not, we divided positive predictive values by 0.892 to give the value for the consulting population. If all cell values in the $2 \times 2$ table were at least five, we stratified analyses by age (40-69 and $\geq 70)$. Analyses were performed with Stata, version 10.

The sample size calculation used abdominal pain. In previous studies, $10 \%$ of the adult population without cancer consulted for abdominal pain. ${ }^{17} 18$ The lowest figure reported before in cases in primary care was $19 \% .{ }^{10}$ To detect such a difference required 210 cases, with a two sided $5 \% \alpha$ and $90 \%$ power.

\section{RESULTS}

\section{Cases and controls}

The computer searches identified 255 women with a record of ovarian cancer; 43 were excluded. Of these, eight were aged $<40$ at diagnosis, 12 were suspected ovarian cancers only (six had other malignancies and six had benign ovarian disease), six had ovarian metastases, and six had recurrences of ovarian cancers initially diagnosed before 2000. Seven diagnoses had been made outside the study area, three had left the study area and their notes could not be retrieved, and one women had the wrong date of birth inadvertently recorded for the study, so her controls were 13 years younger, invalidating them from study. This left 212 cases, including 113 (53\%) women who had died at the time of study but whose notes were retrievable. Each year we identified 12-26 eligible cases, until

\begin{tabular}{lcc}
\hline $\begin{array}{l}\text { Table } 3 \mid \text { Multivariable analysis of symptoms of ovarian cancer in women in primary care } \\
\text { Symptom }\end{array}$ & Odds ratio $(95 \% \mathrm{Cl})$ & P value \\
Symptom: & $240(46$ to 1200$)$ & $<0.001$ \\
\hline Abdominal distension & $24(9.3$ to 64$)$ & $<0.001$ \\
\hline Postmenopausal bleeding & $17(6.1$ to 50$)$ & $<0.001$ \\
\hline Loss of appetite & $16(5.6$ to 48$)$ & $<0.001$ \\
\hline Urinary frequency & $12(6.1$ to 22$)$ & $<0.001$ \\
\hline Abdominal pain & $7.6(2.5$ to 23$)$ & $<0.001$ \\
\hline Rectal bleeding & $5.3(1.8$ to 16$)$ & 0.003 \\
\hline Abdominal bloating & & 0.006 \\
\hline Interaction term: & $0.015(0.00$ to 0.29$)$ & \\
\hline Abdominal distension with urinary frequency & &
\end{tabular}

2006 and 2007, when there were 44 and 52, respectively.

Histology results were available for $169(80 \%)$ of the 212 cases, although 94 of these had no further descriptor other than carcinoma or adenocarcinoma. Of the 75 with the cell type specified, $66(88 \%)$ were epithelial and nine $(12 \%)$ non-epithelial. Thirteen women had borderline tumours. Staging data were available for $164(77 \%)$, with 46 (28\% of those with staging) FIGO stage I, seven (4\%) stage II, $73(45 \%)$ stage III, and 38 $(23 \%)$ stage IV. Of the women aged over $70,51(81 \%)$
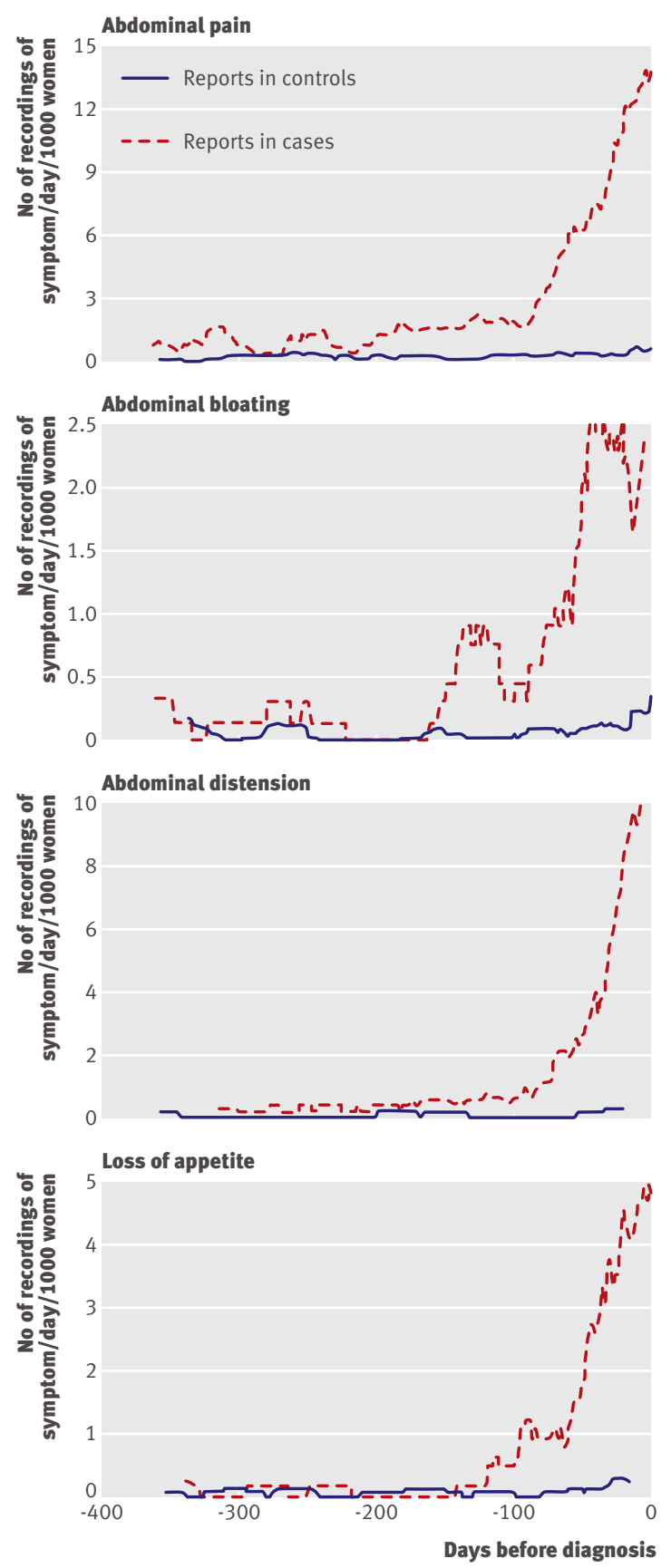

Fig 1| Timing of symptom presentation to primary care in cases and controls. Time 0 is date of diagnosis in case. $Y$ axes have different scales and show number of recordings of symptom each day per 1000 patients 


\begin{tabular}{|l|c|c|c|c|c|}
\hline & $\begin{array}{c}\text { Abdominal } \\
\text { bloating }\end{array}$ & $\begin{array}{c}\text { Abdominal } \\
\text { pain }\end{array}$ & $\begin{array}{c}\text { Urinary } \\
\text { frequency }\end{array}$ & $\begin{array}{c}\text { Loss of } \\
\text { appetite }\end{array}$ & $\begin{array}{c}\text { Abdominal } \\
\text { distension }\end{array}$ \\
\hline $\begin{array}{l}\text { Positive predictive value } \\
\text { as single symptom }\end{array}$ & $\begin{array}{c}0.3 \\
(0.2 \text { to } 0.6)\end{array}$ & $\begin{array}{c}0.3 \\
(0.2 \text { to } 0.3)\end{array}$ & $\begin{array}{c}0.2 \\
(0.1 \text { to } 0.3)\end{array}$ & $\begin{array}{c}0.6 \\
(0.3 \text { to } 1.0)\end{array}$ & $\begin{array}{c}2.5 \\
(1.2 \text { to 5.9) }\end{array}$ \\
\hline Abdominal bloating & 2.0 & $\begin{array}{c}0.8 \\
(0.4 \text { to } 2.2)\end{array}$ & 1.2 & 3.3 & 3.0 \\
\hline Abdominal pain & - & $\begin{array}{c}0.7 \\
(0.4 \text { to } 1.1)\end{array}$ & $\begin{array}{c}0.4 \\
(0.2 \text { to } 0.8)\end{array}$ & $\begin{array}{c}1.0 \\
(0.4 \text { to } 2.3)\end{array}$ & 3.1 \\
\hline Urinary frequency & - & - & $\begin{array}{c}0.2 \\
(0.1 \text { to } 0.8)\end{array}$ & NC & 2.2 \\
\hline Loss of appetite & - & - & - & $\begin{array}{c}0.5 \\
(0.2 \text { to } 1.4)\end{array}$ & 25 \\
\hline Abdominal distension & - & - & - & - & 4.3 \\
\hline
\end{tabular}

Fig 2 Positive predictive values (95\% confidence intervals) for ovarian cancer for individual risk markers and for pairs of risk markers in combination (against background risk of $0.04 \%$ ). Confidence intervals not calculated when any value was $<5$ (invariably this was because too few controls had both features). $\mathrm{NC}=$ not calculated, as fewer than five women had the combination
I or II tumours compared with stage III and IV tumours, and in those cancers diagnosed before and after the introduction of the quality and outcomes framework (a payment scheme for UK general practitioners, which encouraged recording of cancer diagnoses).

Multivariable analysis with data excluding the last 180 days identified early features of ovarian cancer (table 4). No interactions were found in this model.

Figure 1 shows the timings of presentations to primary care in relation to diagnosis for the four most common symptoms: abdominal distension, pain, or bloating and loss of appetite. These graphs compare the number of presentations to primary care between cases and controls, expressed as a monthly moving average.

Figure 2 shows positive predictive values for ovarian cancer for the symptoms shown to be independently associated in multivariable analysis individually, in combination with another symptom, and when the same symptom was reported a second time (shown on diagonal). The univariable positive predictive values and multivariable odds ratios (with $95 \%$ confidence intervals) were $2.5 \%(1.2 \%$ to $5.9 \%)$ and $240(46$ to 1200$)$ for abdominal distension; $0.6 \%(0.3 \%$ to $1.0 \%)$ and 17 (6.1 to 50) for loss of appetite; $0.2 \%(0.1 \%$ to $0.3 \%$ ) and 16 (5.6 to 48$)$ for increased urinary frequency; $0.3 \%(0.2 \%$ to $0.3 \%)$ and $12(6.1$ to 22$)$ for abdominal pain; and $0.3 \%(0.2 \%$ to $0.6 \%)$ and $5.3(1.8$ to 16) for abdominal bloating. For abdominal distension with loss of appetite, 20 cases but no controls had the combination; while strictly speaking undefined, the positive predictive value must logically be very high and so it has been set as $>5 \%$. For postmenopausal and rectal bleeding, the numbers were too small for calculation of positive predictive values in combinations, but the univariable positive predictive values were $0.5 \%$ (95\% confidence interval $0.2 \%$ to $0.9 \%$ ) for postmenopausal bleeding and $0.2 \%(0.1 \%$ to $0.4 \%)$ for rectal bleeding. All the symptoms in figure 2, except for urinary frequency, had higher positive predictive values in patients aged $\geq 70$, reflecting the higher incidence of ovarian cancer in older women.

\section{DISCUSSION}

We found seven symptoms reported to primary care that were independently associated with ovarian cancer. Three of these symptoms - abdominal pain, abdominal distension, and urinary frequencyremained associated with the outcome when we restricted analysis to symptoms reported at least 180 days before diagnosis. All the symptoms have been reported before in secondary care studies. This is encouraging given the large number of various symptoms reported to general practice, all of which entered the analyses in the study. We calculated the risk of ovarian cancer across the whole range of important symptoms in the setting where diagnostic delays are most prevalent-primary care.
180 days before diagnosis

\begin{tabular}{lcc} 
Symptom & Odds ratio $(95 \% \mathrm{Cl})$ & P value \\
Abdominal distension & $18(2.1$ to 160$)$ & 0.009 \\
\hline Urinary frequency & $3.1(1.3$ to 7.3$)$ & 0.009 \\
\hline Abdominal pain & $2.6(1.5$ to 4.6$)$ & 0.001 \\
\hline
\end{tabular}




\section{WHAT IS ALREADY KNOWN ON THIS TOPIC}

Most women with ovarian cancer present with symptoms

Delays in diagnosis are common, and most women have advanced disease at diagnosis

\section{WHAT THIS STUDY ADDS}

The symptoms of ovarian cancer in women presenting to primary care are similar to those in hospital series

Abdominal distension is common, with a positive predictive value for ovarian cancer of $2.5 \%$, and warrants rapid investigation

\section{Strengths and weaknesses}

This study took place in 39 practices and inevitably some variation in recording of symptoms will have been present. The practice matching of controls and use of the same coder for each practice should have minimised the effect of this. Doctors might record symptoms more thoroughly if they consider ovarian cancer as a possibility. If so, the positive predictive values in this study will have been overestimated. Only one positive predictive value has been estimated before: $0.3 \%$ for abdominal pain. ${ }^{10}$ Our similar figure is encouraging, suggesting that recording bias might have had only a small effect. In this study, $15 \%$ of women had none of the seven symptoms recorded in their notes. Interview studies suggest that only $7 \%$ of women truly have no symptoms. ${ }^{9}$ The difference might reflect non-presentation of symptoms to the doctor or failure to record them, or, more probably, both. Furthermore, retrospective methods can rarely capture qualifiers of symptoms, such as severity or duration. Nevertheless, previous studies with medical records have a mean of 22\% (range 19-26\%) of women with cancer who apparently have no symptoms. ${ }^{9}$ Our methods probably enabled us to capture more symptoms than other studies.

We identified the cases by computer searches, and some cases were probably missed. The national incidence figure suggests we should have identified around 35 new cases each year from our study population. The number was smaller than this for the first five years, increasing in 2006, perhaps as a result of the quality and outcomes framework, which encouraged UK general practitioners to establish a cancer register. This discrepancy matters only if the cases we did find are unrepresentative of the total population of women with ovarian cancer. The age distribution is similar to national figures ${ }^{19}$ and the histology and staging similar to other case series, ${ }^{810-12}$ so any bias introduced by missed cases is likely to have been minor.

\section{Symptoms}

All symptoms had positive predictive values below $1 \%$, except for abdominal distension. These low values reflect both the high frequency of abdominal symptoms in the "healthy" population allied to the relatively low incidence of ovarian cancer. Nevertheless, a 2.5\% risk of ovarian cancer with abdominal distension clearly warrants investigation. This symptom was also reported by over a third of women. Furthermore, it remained associated with cancer even when we removed the final six months from analysis. It was also equally as common in stages I and II cancer as it was in advanced cancer, as has been noted before. ${ }^{20}$ Yet, abdominal distension is not included in current guidance for urgent investigation ${ }^{7}$; if it were, some women could have their diagnosis expedited by many months.

An allied symptom is bloating. This is not a mainstream medical term in the UK, and it is likely that the records of bloating represent a verbatim note of the word the woman used. Women, however, use the term for two different symptoms: either persistent (or progressive) distension or intermittent distension. ${ }^{21}$ The latter is the more common use. In this study, those with a record of abdominal distension will include some women whose use of the word "bloating" had been replaced by the term distension, once the exact symptom had been clarified. Other doctors will have retained the term bloating. The converse is less likely, of patients using the term distension yet actually experiencing intermittent swelling. Thus, the abdominal distension variable is likely to be relatively "pure," containing largely patients with persistent distension, whereas the bloating variable probably includes some women more correctly described as having distension. Most previous studies have accepted the term bloating without further definition and have found it to be associated with ovarian cancer. ${ }^{5682223}$ When the two different meanings were separated, however, one small study found that intermittent distension was not associated with cancer. ${ }^{21}$ Our results are compatible with this only if we accept that some of those labelled bloating had persistent distension. Even if true intermittent distension does carry some risk, it is considerably less than persistent distension, as shown by the much smaller odds ratios and positive predictive values.

Over half of women had a record of abdominal pain, and this was equally common for women with early or advanced cancers. It was also present many months before diagnosis in some women. In contrast with abdominal distension, however, the positive predictive value was relatively low at $0.3 \%$. This is a classic conundrum for those working in primary care: the low risk, but not zero risk, symptom. When a second symptom was present (other than distension) the combination still remained relatively low risk. The medical records rarely pinpointed the exact site of the pain so we cannot know if lower abdominal or pelvic pain was particularly strongly linked with cancer. Although this low risk means that women would not generally be offered investigation based on abdominal pain alone, general practitioners need to consider the small possibility of ovarian cancer. Thus where no clear diagnosis can be made, full clinical examination is required, followed up by review and investigation. In a recently reported trial of screening for ovarian cancer, the yield was around one cancer per 2000 women 
screened..$^{24}$ Furthermore, there was an encouragingly low false positive rate. The yield in the women with symptoms will be much higher, suggesting that it is entirely appropriate for general practitioners to investigate low risk but not no risk women.

The third symptom associated with cancer after removal of the final 180 days was urinary frequency. This symptom has been reported before with ovarian cancer but with no clear association with early or late disease. ${ }^{8}$ It was relatively uncommon compared with abdominal distension or pain and posed less risk than either of those. Logically, other more common causes of urinary frequency will be considered first, but ovarian cancer must be remembered as a diagnostic possibility and investigations considered.

Although these three symptoms were associated with cancer 180 days before diagnosis, the graphs in figure 1 suggest that most reporting of symptoms to general practitioners occurs in the three months before diagnosis. We cannot tell from this study if expediting the diagnosis by this amount would yield clinical benefits; all we can say is that earlier diagnosis - by up to three months - is possible for some women.

Unlike abdominal distension, abdominal pain, and urinary frequency, postmenopausal and rectal bleeding are indications for urgent investigation, though the main initial concerns are uterine and colorectal cancers, respectively. Both of these symptoms were slightly more common in early cancers. This might reflect rapid investigation, albeit for a different cancer. These two symptoms, however, were relatively rare so this early investigation will uncover only a small minority of ovarian cancers.

As well as the seven symptoms that remained associated with cancer after multivariable analysis, several others were also associated in univariable analyses, including constipation and diarrhoea. These have been reported before in case series. ${ }^{56825-28}$ The predictive power of these symptoms, however, was outweighed by the presence of other symptoms. This simplifies things a little for primary care. It is difficult enough to remember to consider ovarian cancer with abdominal pain; doctors need not be so concerned with isolated gastrointestinal symptoms.

\section{Conclusion}

Currently, the only realistic proposition for expediting the diagnosis of ovarian cancer rests with identification of cancer in women with symptoms. Symptoms are common and often reported, even in early, and potentially curable, cancers. In that respect, our results are encouraging: there is some chance of identifying early ovarian cancer by using symptoms. In particular, abdominal distension is a common important symptom and warrants rapid investigation. Other symptoms require more traditional primary care skills: history taking, examination, and considering the possibility of cancer. Ovarian cancer is not silent, rather its sound is going unheard.
We thank all participating general practices: Axminster, Bow, Bramblehaies, Budleigh, Castle Place, Chagford, Charters, Cheriton Bishop, Clare House, Claremont, Coleridge, Devonshire House, Hatherleigh, Hill Barton, Honiton, Ide Lane, Imperial, Morchard Bishop, Mount Pleasant (×2), Newcombe, Okehampton, Okement, Pinhoe, Raleigh, Rolle, School, Seaton and Colyton, Sidmouth, Southernhay, South Lawn, St Leonards, St Thomas, Topsham, Townsend House, Westbank, Whipton, Wonford Green, and Woodbury. We also thank research assistants Jackie Barrett, Cath Stabb, and Sally Stapley. Contributors: WH was involved in all aspects of the study, performed the initial analyses, and wrote the initial and revised versions of the paper. DS, TJP, and CB were involved in design, supervision, analysis, and revision of the manuscript. All authors had full access to all of the data (including statistical reports and tables) in the study and can take responsibility for the integrity of the data and the accuracy of the data analysis. WH is the guarantor

Funding: This study was funded by the Department of Health's NIHR School for Primary Care Research funding scheme. The views expressed in this publication are those of the authors and not necessarily those of the Department of Health. Additionally, WH is funded through an NCCRCD postdoctoral fellowship, and his research practice in Exeter received funding from the Department of Health's Research Practices scheme. The study sponsor was the University of Bristol. The authors were independent from the funder and sponsor, who had no role in conduct, analysis or the decision to publish.

Competing interests: None declared.

Ethical approval: The study was approved by the North and East Devon research ethics committee.

1 Quaye L, Gayther SA, Ramus SJ, Di Cioccio RA, McGuire V, Hogdall E, et al. The effects of common genetic variants in oncogenes on ovarian cancer survival. Clin Cancer Res 2008;14:5833-9.

2 Berrino F, De Angelis R, Sant M, Rosso S, Lasota MB, Coebergh JW, et al. Survival for eight major cancers and all cancers combined for European adults diagnosed in 1995-99: results of the EUROCARE-4 study. Lancet Oncol 2007;8:773-83.

3 Colombo N, Van Gorp T, Parma G, Amant F, Gatta G, Sessa C, et al. Ovarian cancer. Crit Rev Oncol Hematol 2006;60:159-79.

4 Rufford BD, Jacobs IJ, Menon U. Feasibility of screening for ovarian cancer using symptoms as selection criteria. BJOG 2007;114:59-64.

5 Goff BA, Mandel L, Muntz HG, Melancon CH. Ovarian carcinoma diagnosis. Cancer 2000;89:2068-75.

6 Goff B, Mandel L, Melancon C, Muntz H. Frequency of symptoms of ovarian cancer in women presenting to primary care clinics. JAMA 2004;291:2705-12.

7 NICE. Referral guidelines for suspected cancer. London: NICE, 2005

8 Vine MF, Calingaert B, Berchuck A, Schildkraut JM. Characterization of prediagnostic symptoms among primary epithelial ovarian cance cases and controls. Gynecol Oncol 2003;90:75-82.

9 Bankhead C, Kehoe S, Austoker J. Symptoms associated with diagnosis of ovarian cancer: a systematic review. BJOG 2005;112:857-65.

10 Friedman GD, Skilling JS, Udaltsova NV, Smith LH. Early symptoms of ovarian cancer: a case-control study without recall bias. Fam Pract 2005;22:548-53.

11 Ryerson AB, Eheman C, Burton J, McCall N, Blackman D, Subramanian S, et al. Symptoms, diagnoses, and time to key diagnostic procedures among older US women with ovarian cancer. Obstet Gynecol 2007;109:1053-61.

12 Smith L, Morris C, Yasmeen S, Parikh-Patel A, Cress R, Romano P. Ovarian cancer: Can we make the clinical diagnosis earlier? Cancer 2005;104:1398-407.

13 WONCA. ICPC-2. International classification of primary care. Oxford: Oxford University Press, 1998.

14 Streiner D, Norman G. Health measurement scales. 3rd ed. Oxford: Oxford University Press, 2003.

15 Patel R, Peters TJ, Murphy D, ALSPAC study team. Prenatal risk factors for caesarean section. Analyses of the ALSPAC cohort of 12944 women in England. Int J Epidemiol 2005;34:353-67.

16 Office for National Statistics. Cancer statistics registrations in 2005, England. Newport: HMSO, 2008.

17 Hamilton W, Peters TJ, Round A, Sharp D. What are the clinical features of lung cancer before the diagnosis is made? A population based case-control study. Thorax 2005;60:1059-65.

18 Hamilton W, Round A, Sharp D, Peters T. Clinical features of colorectal cancer before diagnosis: a population-based case-control study. Br J Cancer 2005;93:399-405.

19 Cancer Research UK. CancerStats 2007. London: Cancer Research UK, 2007. 
20 Latifeh I, Marsden DE, Robertson G, Gebski V, Hacker NF. Presenting symptoms of epithelial ovarian cancer. Aust N Z J Obstet Gynaecol 2005;45:211-4.

21 Bankhead C, Collins C, Stokes-Lampard H, Rose P, Wilson S, Clements $\mathrm{A}$, et al. Identifying symptoms of ovarian cancer: a qualitative and quantitative study. BJOG 2008;115:1008-14.

22 Olson SH, Mignone L, Nakraseive C, Caputo TA, Barakat RR, Harlap S. Symptoms of ovarian cancer. Obstet Gynecol 2001;98:212-7.

23 Ferrell B, Smith S, Cullinane C, Melancon C. Symptom concerns of women with ovarian cancer. J Pain Symptom Manage 2003;25:528-38.

24 Menon U, Gentry-Maharaj A, Hallett R, Ryan A, Burnell M, Sharma A, et al. Sensitivity and specificity of multimodal and ultrasound screening for ovarian cancer, and stage distribution of detected cancers: results of the prevalence screen of the UK collaborative trial of ovarian cancer screening (UKCTOCS). Lancet Oncol 2009;10:327-40.

25 Olsen CM, Cnossen J, Green AC, Webb PM. Comparison of symptoms and presentation of women with benign, low malignant potential and invasive ovarian tumors. Eur J Gynecol Oncol 2007;28:376-80.

26 Vine MF, Ness RB, Calingaert B, Schildkraut JM, Berchuck A. Types and duration of symptoms prior to diagnosis of invasive or borderline ovarian tumor. Gynecol Oncol 2001;83:466-71.

27 Chan Y, Ng T, Lee W, Ngan H, Wong L. Symptoms, coping strategies, and timing of presentations in patients with newly diagnosed ovarian cancer. Gynecol Oncol 2003;90:651-6.

28 Webb P, Purdie D, Grover S, Jordan S, Dick L-M, Green A. Symptom and diagnosis of borderline, early and advanced epithelial ovarian cancer. Gynecol Oncol 2004;92:232-9.

Accepted: 16 May 2009 